\title{
Genetics Poly Cystic Ovary Syndrome
}

\section{Atekeh Bahadori ${ }^{1,2}$, Afrouz Khazamipour ${ }^{3}$, Dariush D.Farhud ${ }^{4,5}$}

${ }^{1}$ Farhud Genetic Clinic,Tehran, Iran. ${ }^{2}$ Applied Biotechnology Research Center,Tehran Medical sciences Branch, Islamic Azad University, Tehran, Iran. ${ }^{3}$ PHD Student of medical Genetics, Faculty of Medicine, Mashhad University of Medical Sciences. Mashhad. Iran. ${ }^{4}$ School of Public Health, Tehran University of Medical Sciences, Tehran, Iran. ${ }^{5}$ Department of Basic Sciences / Ethics, Academy of Medical Sciences Islamic Republic of Iran, Tehran, Iran.

\begin{abstract}
Background: Polycystic ovarian syndrome is a complicated hereditary disorder which does not have the specific reason and $6-10 \%$ of women at fertility age are involved. In another word, we can say that this syndrome is a familial hereditary syndrome which developed with the combination of environmental and genetic factors. Polycystic ovarian syndrome (PCOS) is related to cardiovascular diseases and has psychological and neurological effects on life quality as well as uterine and breast cancers. The main criteria for the diagnosis of the polycystic ovarian syndrome are chronic anovulation and hyperandrogenism and the sub-criteria are insulin resistance, hirsutism and obesity onset at menarche age, anovulation alternatively is associated with increased testosterone level and DHEA-S. The cause of polycystic ovarian syndrome (PCO) is unknown, but it could be the result of complex genetic factors which are evident at puberty onset, also hereditary and non-hereditary factors could be the cause of polycystic ovarian syndrome (PCO) phenotype. In many women with the polycystic ovarian syndrome, the insulin level is high. It seems that high levels of insulin increase androgens production. High levels of androgens can cause acne, supernumerary hair growth, weight gain, and ovulation problem. Conclusion: Early diagnosis and treatment of polycystic ovarian syndrome could help to reduce long-term complications such as diabetes type II, high blood pressure, heart disease, and stroke.
\end{abstract}

Keywords: Polymorphism- polycystic ovarian syndrome (PCOS)- hyperandrogenism

Asian Pac J Cancer Biol, 1 (4), 97-105

\section{Introduction}

Polycystic Ovary Syndrome PCOS; (Poly Cystic Ovary Syndrome) is the most common endocrine disorder among women. This syndrome is a common prevalence of premenopausal women, ranging from $7-15 \%$ of the world's population. The disease or syndrome was defined by two doctors called Leventah \& Stein in 1935 [1].

The polycystic ovary is a syndrome with a wide spectrum of clinical, biochemical, and ultrasound impairments. At one end, these are merely polycystic ovarian ultrasonography, including ovarian enlargement of greater than $9 \mathrm{ml}$, the presence of $2-8 \mathrm{~mm}$ cysts to 10 or more in There is a surface and increased stroma density, and at the other end there are clinical signs such as oligomenorrhoea (prolonged periods of menstruation), increased blood androgens, hirsutism (thickening of the body's hair) and lack of ovulation [2].
Submission Date: 08/14/2016 Acceptance Date: 11/28/2016

Another important complication of polycystic ovary syndrome is infertility. Research shows that the cause of ovulation is $83 \%$ of the infertile couples of the polycystic ovary syndrome, and $44 \%$ of the polycystic ovaries with ovulatory episodes have been reported in $56 \%$ of the couples who have infertility with unknown reasons. In fact, PCOS also increases the risk of metabolic syndrome MS; (Metabolic Syndrome) [4-5], type 2 diabetes (6.7.8.9.10), and possibly cardiovascular disease [5-11-12-13-14-15-16].

\section{Clinical symptoms}

Polycystic ovary syndrome has widespread clinical symptoms, but patients usually refer to doctors due to three disorders: menstruation irregularities, infertility, and symptoms associated with increased androgenic mercury hirsutism and acne [17].

Patients with PCOS are at risk for other diseases such

\section{Corresponding Author:}

Dr. Afrouz Khazamipour

PHD Student of medical Genetics, Faculty of Medicine, Mashhad University of Medical Sciences .Mashhad .Iran

Email: khazamipourafrouz@yahoo.com 
as obesity, hyperinsulinemia, hyperandrogenemia, insulin resistance, and dyslipidemia, including cardiovascular and thrombotic diseases, which have attracted physiologist's attention and required special medical attention [19-20].

Regarding the effect of obesity on the polycystic ovarian syndrome, it appears that continuous exercise along with a healthy diet increase health [21]. Food can interact with the molecular mechanisms and the balance between physiological functions in the body. The focus is on the genomics of nutrition in the interaction between food ingredients and active bioactive components and the neurogenic and neutro-genomics genome. Genetic diversity is known as an effective factor in the balance between human populations and may also be influenced by daily needs and may increase the possibility of personal nutrition helping to prevent diseases and improve health [22].

Understanding the etiology or PCOS etiologies is difficult. Research shows that in PCOS, a number of endocrine disorders are mutating and exacerbating. These disorders include violations in the functioning of the hypothalamus-pituitary axis, ovarian function, and adrenal function. In fact, PCOS with the abnormal discharge of gonadotropins ( $\mathrm{LH}$ ) and FSH(follicle stimulating hormone), increased ovarian steroid secretion and associated insulin resistance [23].

Increasing the amount of LH leads to an increase in the production of androgens [24]. Increasing the secretion of androgens is one of the most important characteristics of the ovaries in PCOS. In this case, the ovaries produce a significant amount of testosterone, androstenedione, and dehydroupiandrosterone (DHES), but serum testosterone is more common [23].

\section{To diagnose PCOS, the following disorders should be rejected}

CAH; (Congenital Adrenal Hyperplasia), Cushing's syndrome, and androgenetic secretion tumors. PCOS can affect some people's quality of life despite changes such as obesity, infertility, anorexia and nervousness, pelvic pain and depression [26].

Potential reasons for this syndrome are still uncertain. In this syndrome, the inappropriate secretion of gonadotropins is noted, in particular, the increased secretion of LH [26-27]. Major disadvantages of this syndrome are insulin resistance, hyperandrogenism, and changes in the dynamics of gonadotropins. The inadequate FSH secretion seems to be the most likely cause of inability Ovulation [28].

The diagnostic criteria for polycystic ovary syndrome also apply to adolescents. Although clinical manifestations of adult and adolescent women are said to be similar, lack of ovulation and hyperandrogenism, which contribute to the definition of this syndrome, is not always an adequate feature in adolescents with polycystic ovary syndrome, and $59 \%$ of the cycle menstruation up to 3 years after menarche in normal girls is not ovulation [29].

Data on the prevalence of PCOS vary due to the lack of an accepted and global diagnostic benchmark. In the United States, according to the National Institute for
Growth and Wellbeing NIH; (National Institutes of Health) in 1990, Hyperandrogenism or Hyperandrogenemia and Ovulation Disorder without Non-Classic Hyperplasia Adrenals are diagnostic criteria for the disease. While these criteria in Europe, are/include the presence of ovaries full of cysts in ultrasound with one or more symptoms such as oligomenorrhoea, hyperandrogenism, obesity, testosterone elevation or serum LH [30]. Since there are different diagnostic criteria in different parts of the world, the spread of this disease has reported between 17 and $22 \%[31-32]$.

\section{Metabolic Features}

\section{Glucose Intolerance}

For the first time in 1980, it was shown that PCOS and obese women showed a significant increase in plasma glucose and venlaulin compared to non-PCOS and non-obese women [33.34]. 20\% of these women are suffering from glucose tolerance IGT; (Impaird Glucose Tolerance) or type 2 diabetes [35]. Obesity and increased age increase the risk of abnormal glucose tolerance [8]. A family relationship between PCOS and diabetes GDM; (Gestational Diabetes Mellitus) and an increased prevalence of type 1 and type 2 diabetes are seen among PCOS women [36.37.38.39].

\section{Insulin Resistance}

Insulin is a polypeptide hormone secreted from pancreatic beta cells, which plays a major role in glucose homeostasis. Tissues are the target of insulin (liver, muscle, and fat). Stimulating insulin leads to consumption of peripheral glucose in muscle and fat tissue, protein synthesis, cell growth, and differentiation. Insulin increases glycogen storage and inhibits glycogenogenesis, glycogenolysis in the liver, as well as lipolysis [40]. Disruption of insulin secretion and function in PCOS women, seen as amenorrhea or non-ovulation, is more than that of regular women [41].

Obesity, fatty centers in the body and muscle volume all have independent and distinct effects on insulin sensitivity [42]. PCOS women do not show insulin resistance without obesity [43-44-45]. Evidence has shown that insulin sensitivity associated with abdominal obesity is correlated with PCOS [46].

\section{Insulin Function}

Insulin is activated after binding to the receptor, and in PCOS women, a defect occurs after this connection. Insulin, itself, acts as gonadotropin in the normal ovary, but in physiological conditions, it is likely to interact with paracrine ovarian factors such as insulin-like growth factor IGF; (Insulin Like Growth Factor) [47-48].

Insulin appears to have a modest effect on FSH in normal ovarian cells and, In fact, increases the effect on $\mathrm{LH}$, and also affects the production of progesterone and E2 in the normal ovary. The ovary in the PCOS is susceptible to insulin effects. Insulin and FSH have synergistic effects on the production of E2 and granular cells in PCOS, but in most cases, normal ovulation is observed. Insulin is seen 


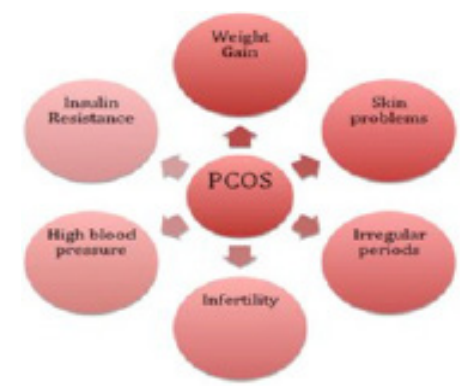

Figure 1. Clinical Manifestations of Polycystic Ovary Syndrome [18]

in high levels of androgen production by ovarian wall cells in PCOS over normal ovaries [49].

\section{Hyper Androgenism \& Insulin Resistance}

High resistance to insulin in this syndrome is usually associated with hyperandrogenic conditions occurring in the premenopausal age. Hyperandrogenic is due to hyperinsulinemia since insulin has a variety of effects on steroidogenesis in humans. Insulin causes hyperandrogenic ovarian and polycystic ovary changes, that are susceptible to high androgen secretion [50].

The role of vitamin D and calcium in the polycystic ovary syndrome

Some evidence suggests that vitamin D deficiency may contribute to the pathogenesis of insulin resistance and metabolic syndrome in PCOS [51-52].

Vitamin D deficiency is common in women with polycystic ovary syndrome (PCOS) and $67-85 \%$ of women with PCOS have 25 -hydroxyvitamin D (HD 250) concentrations ( $20 \mathrm{ml} / \mathrm{ng}$ ). Vitamin D deficiency exacerbates PCOS symptoms. Low levels of HD 250 are associated with insulin resistance, irregularities, and ovulation, low probability of pregnancy, premature fever, hyperandrogenism, obesity and risk factors for cardiovascular disease. Vitamin D deficiency plays an important role in the severity of PCOS [53].

Vitamin D has been shown to affect PCOS by transcribing genes and regulating hormone regulation of insulin metabolism and fertility regulation [54].

Vitamin D deficiency increases PTH, which regulates serum calcium levels and vitamin D. increased PTH

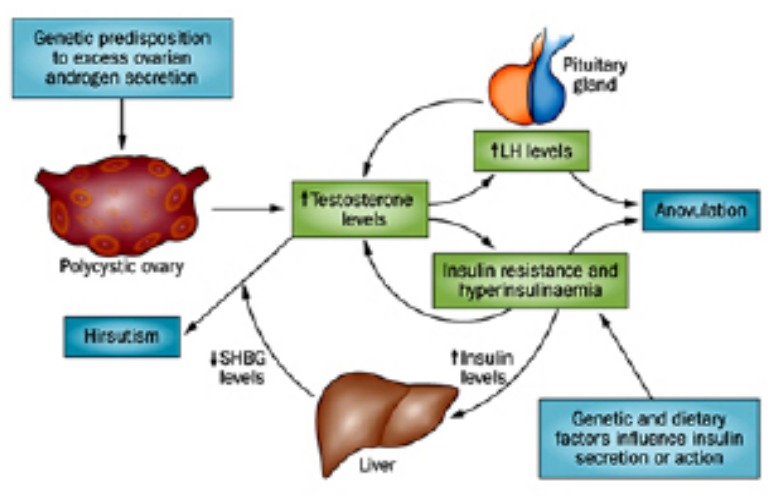

Figure 2. The mechanism of Hormonal Effect on Polycystic Ovary Syndrome [25].

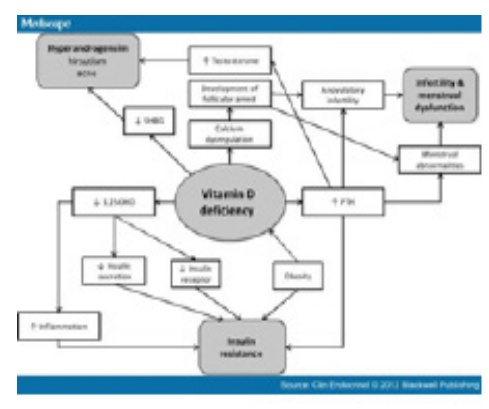

Figure 3. Vitamin D Deficiency Mechanism and Its Effect on Different Parts [62]

associated with PCOS, which results in infertility and increased testosterone [55].

The 2001 Zborowski study showed that PCOS patients are also exposed to osteoporosis, which can be due to insulin function in calcium intake and the effect of homocysteine [56].

Several studies show that elevated levels of parathyroid hormone (PTH) result in high blood pressure following a reduction in serum calcium. Therefore, calcium intake can prevent hypertension and subsequently cardiovascular disease [57-58].

In a study by Yacob on PCOS patients, vitamin D deficiency was observed in these patients despite the abnormality of the extracellular calcium concentration; following a decrease in vitamin $\mathrm{D}$, a decrease in intracellular calcium serum concentrations, as well as abnormal oocyte function, is seen [59].

With numerous studies on animals, the role of calcium in the evolution of the oocyte has also been identified, but its effect is unknown and researchers have investigated the need for the effectiveness of calcium and vitamin D on human ovulation, and especially in PCOS cases [60-61].

\section{Genetic role in polycystic ovary syndrome}

The genetic basis of polycystic ovary syndrome (PCOS) (Stein-Leventhal) was proposed by Cooper and colleagues in 1968 [63].

Although the etiology of this syndrome is still unclear, genetics play an important role in the pathogenesis of the syndrome. In recent decades, much research has been done on accompanying studies of pathogenicity of genes in relation to reproductive hormones, insulin receptors and chronic inflammation [64].

The family history of PCOS and its accompanying features in the study on twins have shown that genetic factors play an important role in the pathogenesis of this disease. In addition, two more symptoms of the disease can be found in families. While the differences in the symptoms of the disease may reflect the different expression or the same effect of the genes [65-66], heterozygosity and the absence of a specific clinical and biochemical diagnostic criterion for PCO has made it difficult to diagnose [67].

\section{PCO Gene Position Identification Methods}

There is a basic and practical dilemma for identifying the position of PCOs: 

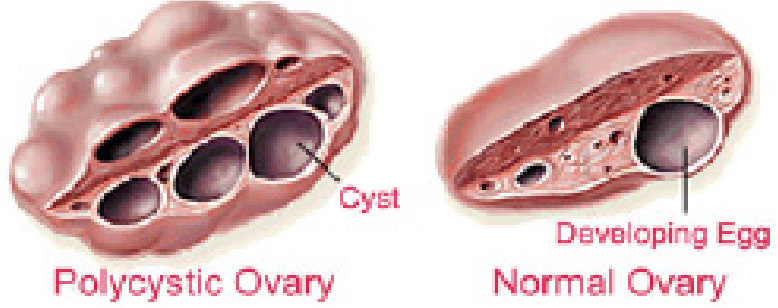

Figure 4. Is a View of a Full Cyst Ovary and a Natural Ovary [68]

1) Association studies where the predisposing allele has the highest frequency in the population of patients than normal people.

2) Linkage studies where Proband and their relatives are designated for a particular genetic status, independent or associated with their phenotypes [69].

Candidate genes include sex hormone genes and regulatory genes, insulin sensitivity, type 2 diabetes, cardiovascular disease [70], insulin genes, insulin receptor, and calapain-10 (36). Studies have shown that the combination of the CALAPINE-10 gene with the PCOS phenotype is well documented [71].

The single-nucleotide polymorphism of $\mathrm{C} / \mathrm{T}$ in exon 17 dimetiosine kinase from the insulin receptor gene (INSR) in this syndrome is shown by the final effects of autophosphorylation from the insulin receptor gene in PCOS women [72-73].

In a study by Hyejin Lee and colleagues on Korean women with polycystic ovary syndrome through GWA in 2014, a new genome with a genomic significance and seven related sites were identified in PCOS. The best relationship was observed in chromosome 8 , on $8 \mathrm{q} 24.2$ (rs10505648, OR./52, $\mathrm{p}=5.46 * 10-8)$, the corresponding signals were identified at the following positions: 4q35.2, $16 \mathrm{p} 13.3,4 \mathrm{p} 12,3 \mathrm{q} 26.33,9 \mathrm{q} 21.32,11 \mathrm{p} 13$ and $1 \mathrm{p} 22$ $(\mathrm{P}=5.72 * 10-6-6.43 * 10-5)$

The strongest signals were in the KHDRBS3 upstream region, which is associated with telomerase function and leads to PCOS and clinical symptoms associated with the syndrome [74].

Evidence suggests that genetic effects include the PCOS family classification, and increased frequency of symptoms such as hyperandrogenism and type 2 diabetes in the first-degree relatives of women with PCOS [65-70].

According to these results, genetic effect defines a risk of PCOS of about $65 \%$ [75].

Recently, genetic link studies on PCOS have become widespread [76]. Several genetic studies have been conducted on PCOS [77.78.79].

GWA studies provide the possibility of analyzing a large number of variables at the same time, as a result of identifying new genes. The first GWA studies were conducted in a group of people with PCOS in China, and the design of the varieties in three positions (2p16.3, 2p21 and 9q33.3) were identified [80].

A secondary GWA in a larger group of Chinese patients with PCOS has identified the design of varieties in eight positions for PCO: $2 \mathrm{p} 16.3,9 \mathrm{q} 22.32,11 \mathrm{q} 22.1$, 12q13.2, 12q14.3, 16q12.1, 19p13.3 and 20q13.2 [81].

Although several genetic factors, including mutations and polymorphisms, are risk factors for PCOS [82], genetic patterns and molecular genetic mechanisms have not been well documented to confirm the potential factors of this syndrome [83].

Autosomal or predominant x-dependent inheritance patterns should be considered. However, PCOS inheritance is often multifactorial, such as type 2 diabetes or cardiovascular diseases [84].

Environmental factors such as obesity or sluggishness affecting the insulin, insulin sensitivity, or function, alter the clinical and biochemical manifestations of people with genetic predisposition to PCOS [44-46].

Telomerase enzyme and its relationship with polycystic ovary syndrome.

Studies have shown that KHDRBS3 gene expression is related to the regulation of telomerase activity in human colon cancer [85].

Telomerase is an enzyme that plays a role in maintaining the length of telomere [86]. Telomere length is inherited and is regulated by a variety of environmental and genetic factors [87].

The short telomerase (?? telomeres or telomerase?) causes chromosomal instability and this condition increases the level of genetic mutations and chromosomal abnormalities. Several studies have shown the role of telomeric length in cancers [88], cardiovascular diseases [89], diabetes [90], and infectious diseases [91]. It turned out that telomere length is associated with PCOS too. Short-acting telomeres disrupt insulin secretion, signaling pathways, mitochondrial function and $\mathrm{Ca}+2$ metabolisms [92.93].

Different characteristics of PCOs, including high androgens, abnormal obesity, and insulin resistance, can lead to telomere shortening; short telomeres affect reproductive and metabolic reproduction and worsen the abnormal metabolic structures [94].

In another study using the original GWA on polycystic ovary syndrome, 11 vulnerabilities were identified in Chinese people. Some of the risk positions that were identified in Chinese people, most often in the early GwA, have also been observed in European populations. The effect of secondary GWA status in European subjects was to determine whether variants similar to PCOS are found in individuals of different races or not. The result of this study was that 4 vulnerabilities in polycystic ovarian syndrome, as seen in Chinese GWA studies, are linked to PCOS in European populations, and the identification of these sites plays an important role in etiology Polycystic ovary syndrome is common in all races [95].

The first extended genome-related study has identified three sites of polycystic ovary syndrome including THADA, LHCGR, and DENND1 A regions [78]. THADA and DENND1A variants were also observed in European subjects (96.97).

In the GWA II studies, eight new sites were identified in Dutch, including areas (FSHR, C9orf3 INSR, HMGA2, YAP1, RAB5B / SUOX, TOX3 SUMO1P1) [81]. 
Table 1. Genotype Panel of Selected Gene [100] (Candidate Gene)

\begin{tabular}{|c|c|c|c|c|}
\hline Marker locus & Gene symbol & Candidate gene & $(\mathrm{cM})^{*}$ & Chromosomal location \\
\hline \multicolumn{5}{|c|}{ Steroid hormone } \\
\hline AR & $\mathrm{AR}$ & Androgen receptor & 0 & $\mathrm{Xq} 11.2$ \\
\hline D15S519 & CYP11A & cytochrome P450 side-chain cleavage.E & 0 & $15 q 23-24$ \\
\hline D15S520 & CYP11A & cytochrome P450 side-chain cleavage.E & 0 & $15 q 23-24$ \\
\hline D10S192 & CYP17 & cytochrome P450 17a-hydroxylase/17,20-desmolase & $<1$ & $10 \mathrm{q} 24.3$ \\
\hline CYP19 & CYP19 & CYP19-cytochrome P450 aromatase & 0 & $15 \mathrm{q} 21$ \\
\hline D17S934 & HSD17B1 & $17 \beta$-hydroxysteroid dehydrogenase, type I & $<2$ & $17 \mathrm{q} 11-21$ \\
\hline HSD17B2 & HSD17B2 & $17 \beta$-hydroxysteroid dehydrogenase, type II & 0 & $16 \mathrm{q} 24.2$ \\
\hline D9S1809 & HSD17B3 & $17 \beta$-hydroxysteroid dehydrogenase, typeIII & $<1$ & $9 \mathrm{q} 22$ \\
\hline D1S514 & HSD3B $1+2$ & $3 \beta$-hydroxysteroid dehydrogenase typeI,II & $<1$ & $1 \mathrm{p} 31.1$ \\
\hline D8S1821 & STAR & Steroidogenic acute regulatory protein & $<2$ & $8 \mathrm{p} 11.2$ \\
\hline \multicolumn{5}{|c|}{ Gonadotropin action } \\
\hline D12S347 & ACTR1 & Activin receptor 1 & $<1$ & $12 \mathrm{q} 13.12$ \\
\hline D2S2335 & ACTR2A & Activin receptor $2 \mathrm{~A}$ & $<1$ & $2 \mathrm{q} 22.2$ \\
\hline D3S1298 & ACTR2B & Activin receptor $2 \mathrm{~B}$ & $<1$ & $3 \mathrm{p} 22.2$ \\
\hline D5S474 & FS & Follistatin & $<2$ & $5 \mathrm{p} 14$ \\
\hline D5S623 & FS & Follistatin & $<1$ & $5 \mathrm{p} 14$ \\
\hline D5S822 & FS & Follistatin & $<1$ & $5 \mathrm{p} 14$ \\
\hline $\mathrm{D} 2 \mathrm{~S} 163$ & INHA & Inhibin A & $<1$ & $2 \mathrm{q} 33.34$ \\
\hline INHBA & INHBA & Inhibin $\beta$-A & 0 & $7 \mathrm{p} 13-15$ \\
\hline D2S293 & INHBB & Inhibin $\beta$-B & 2 & 2 cen- 2 q13 \\
\hline D12S1691 & INHC & Inhibin C & $<1$ & $12 \mathrm{q} 13$ \\
\hline D17S1353 & SHBG & Sex hormone binding globulin & $<1$ & $17 \mathrm{p} 13.2$ \\
\hline $\mathrm{D} 2 \mathrm{~S} 1352$ & LHCGR & Luteinizing hormone/choriogonadotropin $\mathrm{R}$ & $<2$ & $2 \mathrm{p} 21$ \\
\hline $\mathrm{D} 2 \mathrm{~S} 1352$ & FSHR $\dagger$ & Follicle-stimulating hormone receptor & $<2$ & $2 \mathrm{p} 21$ \\
\hline D18S474 & MADH4 & Mothers against decapentaplegic homolog4 & $<1$ & $18 \mathrm{q} 21$ \\
\hline \multicolumn{5}{|c|}{ Obesity and energy regulation } \\
\hline D18S64 & MC4R & Melanocortin 4 receptor & $<3$ & $18 \mathrm{q} 21.32$ \\
\hline D7S1875 & OB & Leptin & 0.2 & $7 \mathrm{q} 31.3-32.1$ \\
\hline D1S198 & OBR & Leptin receptor & 0.5 & $1 \mathrm{p} 31$ \\
\hline $\mathrm{D} 2 \mathrm{~S} 131$ & POMC & Pro-opiomelanocortin & $<1$ & $2 \mathrm{p} 23$ \\
\hline D11S911 & $\mathrm{UCP} 2+3$ & Uncoupling protein $2+3$ & $<4$ & $11 \mathrm{q} 13$ \\
\hline \multicolumn{5}{|l|}{ Insulin action } \\
\hline IGF1 & IGF1 & Insulin-like growth factor I & 0 & $12 q 22-23$ \\
\hline IGF1R & IGF1R & Insulin-like growth factor I receptor & 0 & $15 \mathrm{q} 25-26$ \\
\hline D7S519 & IGFBP $1+3$ & Insulin-like growth factor binding protein $1+3$ & 1 & $7 \mathrm{p} 13-7 \mathrm{p} 12$ \\
\hline HphI site & INS VNTR & Insulin gene VNTR & 0 & $11 \mathrm{p} 15.5$ \\
\hline INSR & INSR & Insulin receptor & 0 & $19 \mathrm{p} 13.3$ \\
\hline D19S216 & INSR & Insulin receptor & 4.2 & $19 \mathrm{p} 13.3$ \\
\hline D19S905 & INSR & Insulin receptor & 0 & $19 \mathrm{p} 13.3$ \\
\hline D19S884 & INSR & Insulin receptor & 1.2 & $19 \mathrm{p} 13.3$ \\
\hline D19S922 & INSR & Insulin receptor & 1.2 & $19 \mathrm{p} 13.3$ \\
\hline D19S391 & INSR & Insulin receptor & 3.6 & $19 \mathrm{p} 13.2$ \\
\hline D19S865 & INSR & Insulin receptor & 7.2 & $19 \mathrm{p} 13.2$ \\
\hline D19S906 & INSR & Insulin receptor & 11 & $19 \mathrm{p} 13.2$ \\
\hline D19S840 & INSR & Insulin receptor & 14 & $19 \mathrm{p} 13.2$ \\
\hline D19S212 & INSL3 & Leydig insulin-like protein 3 & $<1$ & $19 \mathrm{p} 13.1$ \\
\hline D19S410 & INSL3 & Leydig insulin-like protein 3 & $<1$ & $19 \mathrm{p} 13.1$ \\
\hline IRS1 & IRS1 & Insulin receptor substrate 1 & 0 & $2 \mathrm{q} 36-37$ \\
\hline D3S1263 & PPARG & Peroxisome proliferator-activated receptor- $\gamma$ & $<0.2$ & $3 \mathrm{p} 25-24.2$ \\
\hline
\end{tabular}


Recent studies suggest that DENND1 mRNA and protein in ovarian cells increase in polycystic ovarian syndrome and androgen biosynthesis enhance [98], taking into account the GWA's position in Chinese subjects.

The LHCGR promoter region in granulosa cells has been subjected to hypomethylation in women with PCOS, leading to increased transcription of LHCGR [99].

37 selected genes from 4 metabolic pathways are involved in the etiology of this syndrome and are restricted to 33 chromosomal regions. These regions have been discovered by determining the 45 genotypes of the continuous polymorphic site with 37 selected genes [100].

\section{Discussion}

Polycystic ovary syndrome (PCOS) is the most common endocrine disorder in women of reproductive age. Although PCOS does not show Mendelian hereditary patterns, it identifies the role of genetic factors in its formation. A large number of candidate genes have a function, with the phenotypes of the syndrome, with positive and negative results, accompanied or consistent [100].

Govind et al. (1999) identified the genetic basis of the syndrome in 29 countries with PCOS and 10 healthy women. The results of this study clearly show the prevalence of autosomal dominant inheritance with male evaluation (baldness of the head) and positive ultrasound scan at postmenopausal age, a positive history of postmenopausal women. Also, no ultrasound manifestations and familial history of PCOS were observed in normal women group, and these results indicate that the phenotype of the disease has a genetic basis [101].

A comprehensive study of Urbanek et al in 1994, identified the PCOS-related genetic linkage in a group of 367 families, including individuals typical of the syndrome in European regions [102].

In 2003, Gonzalez and colleagues examined the combination of SNP(SNP19-SNP63-SNP43-SNP44) of the calpain-10 gene, suggesting that SNP44 was associated with PCOS in Spanish women [71-103].

A study by Talbott E and colleagues suggests that a new position has been identified in PCOS. Several genes involved in this disorder are associated with dyslipidemia, endometriosis, insulin resistance, and inflammatory signals [14].

The use of genetics in the field of medicine has made remarkable progress in recent years. When genetic knowledge, as well as other knowledge, is used in a suitable way, it can play an important role in contributing to the health of humans. The new developments and achievements of this knowledge are only accepted when they are in line with ethical standards, respecting autonomy, individual and social justice, the beliefs and laws of particular nations and different human societies [104].

In Conclusion, according to a review of the PCO and the genetic mechanism involved in the disease, it should be noted that there may be a link between these factors and the disease process, which confirms this to prevent the progression of the disease to further study in this area. Further studies are needed in this field due to, as well as considering that the role of the genetic and environmental factors that lead to the development of PCOS and their interaction with each other is still not well-known. The better understanding of these factors and reactions can help to more effectively diagnose and develop new therapies.

\section{References}

1.Stein IF, Leventhal ML. Amenorrhea associated with bilateral polycystic ovaries. Am J Obstet Gynecol. 1935;29(2):18191

2.Edwards RG, Beard HK. Is the success of human IVF more a matter of genetics and evolution thangrowing blastocysts? Hum Reprod. 1999 Jan; 14(1): 1-4.

3.Engmann L, Maconochie N, Sladkevicius P, Bekir J, Campbell S, Tan SL. The outcome of in-vitrofertilization treatment in women with sonographic evidence of polycystic ovarian morphology. HumReprod. 1999 Jan; 14(1): 167-71 .

4.Glueck CJ, Papanna R, Wang P, Goldenberg N,Sieve-Smith L. Incidence and treatment of metabolicsyndrome in Expert Rev. Obstet. G 86 ynecol. 5(1),(2010) Review Massicotte, Langlois \& Baillargeonnewly referred women with confirmed polycysticovarian syndrome. Metabolism 52(7), 908-915(2003)

5.Vural B, Caliskan E, Turkoz E, Kilic T, Demirci A.Evaluation of metabolic syndrome frequency andpremature carotid atherosclerosis in young womenwith polycystic ovary syndrome. Hum. Reprod.20(9), 2409-2413 (2005).

6.Gambineri A, Pelusi C, Manicardi E et al. Glucoseintolerance in a large cohort of mediterranean womenwith polycystic ovary syndrome: phenotype andassociated factors. Diabetes 53(9), 2353-2358 (2004).

7.Weerakiet S, Srisombut C, Bunnag P, Sangtong S, Chuangsoongnoen N, Rojanasakul A. Prevalence ofType 2 diabetes mellitus and impaired glucosetolerance in Asian women with polycystic ovarysyndrome. Int. J. Gynaecol. Obstet. 75(2), 177-184(2001).

8.Legro RS, Kunselman AR, Dodson WC, Dunaif A.Prevalence and predictors of risk for Type 2 diabetesmellitus and impaired glucose tolerance in polycysticovary syndrome: a prospective, controlled study in 254 affected women. J. Clin. Endocrinol. Metab.84(1), 165-169 (1999).

9.Ehrmann DA, Barnes RB, Rosenfield RL,Cavaghan MK, Imperial J. Prevalence of impairedglucose tolerance and diabetes in women withpolycystic ovary syndrome. Diabetes Care 22(1),141-146 (1999).

10.Legro RS, Gnatuk CL, Kunselman AR, Dunaif A.Changes in glucose tolerance over time in womenwith polycystic ovary syndrome: a controlled study. J.Clin. Endocrinol. Metab. 90(6), 3236-3242 (2005).

11.Cascella T, Palomba S, De Sio I ,et al. Visceral fatis associated with cardiovascular risk in women withpolycystic ovary syndrome. Hum. Reprod. 23(1), 53-159 (2008).

12.Shroff R, Kerchner A, Maifeld M, Van Beek EJ,Jagasia D, Dokras A. Young obese women withpolycystic ovary syndrome have evidence of earlycoronary atherosclerosis. J. Clin. Endocrinol. 92(12), 4609-4614 (2007).

13.Lakhani K, Hardiman P, Seifalian AM. Intima-media thickness of elastic and muscular arteries ofyoung women with polycystic ovaries.Atherosclerosis 175(2), 353-359 (2004) 
14.Talbott E, Zborowski J, Rager J, Boudreaux M, Edmundowicz D, Guzick D. Evidence for an association between metabolic cardiovascular syndrome and coronary and aortic calcification among women with polycystic ovary syndrome. Journal of Clinical Endocrinology \& Metabolism. 2004;89(11):5454-61

15.Orio F Jr, Palomba S, Cascella T, et al. Earlyimpairment of endothelial structure and function inyoung normal-weight women with polycystic ovarysyndrome. J. Clin. Endocrinol. Metab. 89(9), 4588-4593 (2004).

16.Solomon CG, Hu FB, Dunaif A et al. Menstrualcycle irregularity and risk for future cardiovasculardisease. J. Clin. Endocrinol. Metab. 87(5), 2013-2017(2002). Metab.

17.Tsilchorozidou T, Overton C, Conway GS, Thepathophysiology of polycystic ovary syndrome. ClinEndocrinol (Oxf). 60 (2004) 1-17.

18.https://www.todayhealthtips.com/pcos

19.Kazerooni T, Asadi N, Dehbashi S, Zolghadri J, Effectof folic acid in women with and without insulinresistance who have hyperhomocysteinemic polycysticovary syndrome. Int J Gynaecol Obstet. 101 (2008)156-160.

20.Palep-Singh M, Picton HM, Yates ZR, Barth JH, BalenAH, Plasma homocysteine concentrations and the singlenucleotide polymorphisms in the methionine synthasegene (MTR $2756 \mathrm{~A}>\mathrm{G})$ : Associations with the polycysticovary syndrome An observational study. Eur J ObstetGynecol Reprod Biol. 138 (2008) 180-186.

22.Farhud DD,Malmir M,khanahmadi M(2015).Happiness as a healthy lifestyle Iranian Academy of Medical Science. Iran J Public Health, Vol. 44, No.11, Nov 2015, pp.1442-1444

23. DD Farhud, M Zarif Yeganeh,nutrigenomics and nutrigenetics. Iranian J Publ Health, Vol. 39, No.4, 2010, pp.1-14.

23.Marx TL, Mehta AE. Polycystic ovary syndrome:pathogenesis and treatment over the short and long term.Cleveland Clinic J Med 70 (2003) 31-45.

24.Speroff L, Fritz M. Anovulation and the polycysticovary. Clinical Gynecology Endocrinology andInfertility. 2005; 7th Edition: 465-498.

25.http://www.nature.com/nrendo/journal/v10/n10/full/ nrendo.2014.102.html

26. Marc A. Fritz And Leon Speroff Clinical Gynecologic Endocrinology and Infertility-2011,Volume1

27.McARTHUR JW, INGERSOLL FM, WORCESTER J. The urinary excretion of interstitial-cell and follicle-stimulating hormone activity by women with diseases of the reproductive system. Journal of Clinical Endocrinology \& Metabolism. 1958;18(11):1202-15

28. Yen S. C., Vela, P. and Rankin, J.(1970). Inappropriate secretion of follicle- stimulating hormone and luteinizing hormone in polycystic ovarian disease. J Clin Endocrinol Metab.30:435-42

29. Chang PL, Lindheim SR, Lowre C, Ferin M, Gonzalez F, Berglund L, et al. Normal ovulatory women with polycystic ovaries have hyperandrogenic pituitary-ovarian responses to gonadotropin-releasing hormone-agonist testing. Journal of Clinical Endocrinology \& Metabolism. 2000;85(3):9951000 .

30.Apter D, Vihko R. Premenarcheal endocrine changes in relation to age at menarche. Clinical endocrinology. 1985;22(6):753-60

31.Balen AH, Conway GS, Kaltsas G, Techatraisak K, Manning PJ, West C, et al. Andrology: Polycystic ovary syndrome: the spectrum of the disorder in 1741 patients.

32.Carmina E, Lobo RA. Polycystic ovary syndrome (PCOS): arguably the most common endocrinopathy is associated with significant morbidity in women. Journal of Clinical
Endocrinology \& Metabolism. 1999;84(6):1897-9.

33.Atiomo WU, Condon J, Adekanmi O, Friend J, Wilkin TJ, Prentice AG. Are women with polycystic ovary syndrome resistant to activated protein C? Fertility and sterility. 2000;74(6):1229-32.

34.BURGHEN GA, GIVENS JR, KITABCHI AE. Correlation of hyperandrogenism with hyperinsulinism in polycystic ovarian disease. Journal of Clinical Endocrinology \& Metabolism. 1980;50(1):113-6.

35.Duaif A, Graf M, Mandeli J, LaumasV, Dobrjansky A. Characterization of Groups of Hyperaiidrogenic Women with Acanthosis Nigricans, Impaired Glucose Tolerance, and/or Hyperinsulinemia. Journal of Clinical Endocrinology \& Metabolism. 1987;65(3):499-507.

36.Escobar-Morreale HF, Roldán B, Barrio R, Alonso M, Sancho $\mathrm{J}$, de la Calle $\mathrm{H}$, et al. High prevalence of the polycystic ovary syndrome and hirsutism in women with type 1 diabetes mellitus. Journal of Clinical Endocrinology \& Metabolism. 2000;85(11):4182-7.

37.LANZONE A, CARUSO A, DI SIMONE N, DE CAROLIS S, Fulghesu A, MANCUSO S. Polycystic ovary disease: A risk factor for gestational diabetes? Journal of reproductive medicine. 1995;40(4):312-6.

38.Lanzone A, Fulghesu A, Cucinelli F, Guido M, Pavone V, Caruso A, et al. Endocrinology: Preconceptional and gestational evaluation of insulin secretion in patients with polycystic ovary syndrome. Human reproduction. 1996;11(11):2382-6.

39.Conn JJ, Jacobs HS, Conway GS. The prevalence of polycystic ovaries in women with type 2 diabetes mellitus. Clinical endocrinology. 2000;52(1):81-6.

40.Cheatham B, Kahn CR. Insulin action and the insulin signaling network. Endocrine reviews. 1995;16(2):117-42.

41.Robert Y, Dubrulle F, Gaillandre L, Ardaens Y, ThomasDesrousseaux P, Lemaitre L, et al. Ultrasound assessment of ovarian stroma hypertrophy in hyperandrogenism and ovulation disorders: visual analysis versus computerized quantification. Fertility and sterility. 1995;64(2):307.

42.Farah L, Lazenby A, Boots L, Azziz R. Prevalence of polycystic ovary syndrome in women seeking treatment from community electrologists. Journal of reproductive medicine. 1999;44(10):870-4.

43.Ovesen P, Moller J, Ingerslev HJ, Jørgensen J, Mengel A, Schmitz O, et al. Normal basal and insulin-stimulated fuel metabolism in lean women with the polycystic ovary syndrome. Journal of Clinical Endocrinology \& Metabolism. 1993;77(6):1636-40

44.Morin-Papunen LC, Vauhkonen I, Koivunen RM, Ruokonen A, Tapanainen JS. Insulin sensitivity, insulin secretion, and metabolic and hormonal parameters in healthy women and women with polycystic ovarian syndrome. Human reproduction. 2000;15(6):1266-74.

45.Bringer J, Lefebvre P, Boulet F, Grigorescu F, Renard E, Hedon B, et al. Body Composition and Regional Fat Distribution in Polycystic Ovarian Syndrome Relationship to Hormonal and Metabolic Profiles. Annals of the New York Academy of Sciences. 1993;687(1):115-23.

46. Holte J, Bergh T, Berne C, Wide L, Lithell H. Restored insulin sensitivity but persistently increased early insulin secretion after weight loss in obese women with polycystic ovary syndrome. Journal of Clinical Endocrinology \& Metabolism. 1995;80(9):2586-93.

47.Willis D, Mason H, Gilling-Smith C, Franks S. Modulation by insulin of follicle- stimulating hormone and luteinizing hormone actions in human granulosa cells of normal and polycystic ovaries. Journal of Clinical Endocrinology \& 
Metabolism. 1996;81(1):302-9.

48.Willis DS, Watson H, Mason HD, Galea R, Brincat M, Franks S. Premature response to luteinizing hormone of granulosa cells from anovulatory women with polycystic ovary syndrome: relevance to mechanism of anovulation. Journal of Clinical Endocrinology \& Metabolism. 1998;83(11):3984-91.

49.Nestler JE, Jakubowicz DJ, de Vargas AF, Brik C, Quintero N, Medina F. Insulin stimulates testosterone biosynthesis by human thecal cells from womenpolycystic ovary syndrome by activating its own receptor and using inositolglycan mediators as the signal transduction system. Journal of Clinical Endocrinology \& Metabolism. 1998;83(6):2001-5.

50.Dunaif A, Graf M. Insulin administration alters gonadal steroid metabolism independent of changes in gonadotropin secretion in insulin-resistant women with the polycystic ovary syndrome. Journal of Clinical Investigation. 1989;83(1):23

51.Wehr, E., Pilz, S., Schweighofer, N. (2009) Association of hypovitaminosis $\mathrm{D}$ with metabolic disturbances in polycystic ovary syndrome. European Journal of Endocrinology, 0, EJE-9- EJE0432.

52.Ngo, D.T.M., Chan, W.P., Rajendran, S. (2011) Determinants of insulin responsiveness in young women: Impact ofpolycystic ovarian syndrome, nitric oxide, and vitamin D. NitricOxide, 25, 326-330.

53.Rebecca L. Thomson, Simon Spedding and Jonathan D. BuckleyVitamin D in the aetiology and management of polycystic ovarysyndromeClinical Endocrinology (2012) 77, 343-350

54.Mahmoudi, T., Gourabi, H., Ashrafi, M. (2010) Calciotropic hormones, insulin resistance, and the polycystic ovary syndrome. Fertility and Sterility, 93, 1208-1214.

55.Panidis, D., Balaris, C., Farmakiotis, D. (2005) Serum parathyroidhormone concentrations are increased in women withpolycystic ovary syndrome. Clinical Chemistry, 51, 1691-1697.

56.Zborowski JV, Talbtt EO, Cauley JA. Polycystic ovarysyndrome, androgen excess, and the impact on bone. Obstet Gynecol Clininical North Am. 2001; 28(1):135-51.

57.Jorde R, Sundsfyord J, Haug E, Bonaa KH. Relationbetween low calcium intake, parathyroid hormone, andblood pressure. Hypertention 2000;35:1154-9.

58.Bostick RM, Kushi LH, Wu Y, Meyer KA, SellersTA, Folsom AR. Relation of calcium, vitamin D, anddairy food intake to ischemic heart disease mortalityamong postmenopausal women. Am J Epidemiol 1999;149:151-61

59. Thys- Yacobs S, Donovan D, Papadopoulos A, SarrelP,Bilezikian J.P. Vitamin D and Calcium dysregulationin the polycystic ovarian syndrome. Steroids 1999; 64:430-5.

60.Homa ST, Carroll J, Swann K. The role of calcium inmammalian oocyte maturation and egg activation.Hum Reprod 1993;8:1274-81.

61.Kaufman M, Homa ST. Defining a role for calcium inthe resumption and progression of meiosis in the pigoocyte. $\mathrm{J}$ Exp Zool. 1993;265:69-76.

62.Rebecca L.Thomson,simon spending and jonathan D.Buckley. vitamin $\mathrm{D}$ in the aetiology and management of polycystic ovary syndrome.clinical Endrocrinology.2012:77.343-350.

63.Cooper HE, Spellacy W, Prem K, Cohen W. Hereditary factors in the Stein-Leventhal syndrome. American journal of obstetrics and gynecology. 1968;100(3):371.

64.Chen Z, Shi Y, Zhao Y, Li Y, Tang R, Zhao L, et al. Correlation between single nucleotide polymorphism of insulin receptor gene with polycystic ovary syndrome. Zhonghua fu chan ke za zhi. 2004;39(9):582

65.Legro RS, Driscoll D, Strauss JF III, Fox J, Dunaif A.
Evidence for a genetic basisfor hyperandrogenemia in polycystic ovary syndrome. Proc Natl Acad SciUSA 1998;95:14956-14960.

66.Franks, S. Ovarian morphology is a marker of heritable biochemical traits in sisters with polycystic ovaries. J. Clin. Endocrinol. Metab. 93, 3396-3402(2008).

67.Franks S, Gharani N, Waterworth D, Batty S, White D, Williamson R, et al. The genetic basis of polycystic ovary syndrome. Human reproduction. 1997;12(12):2641- 8.

68.http://www.fertilitysudan.com/pco.php

69. March RE. Gene mapping by linkage and association analysis. Molecular biotechnology. 1999;13(2):113-22.

70.Ehrmann DA. Polycystic ovary syndrome. New England Journal of Medicine. 2005;352(12):1223-36.

71.Conway GS, Avey C, Rumsby G. Genetics: The tyrosine kinase domain of the insulin receptor gene is normal in women with hyperinsulinaemia and polycystic ovary syndrome. Human reproduction. 1994;9(9):1681-3.

72.Ehrmann DA. 7 Relation of functional ovarian hyperandrogenism to non-insulin dependent diabetes mellitus. Baillière's clinical obstetrics and gynaecology. 1997;11(2):335-47.

73.Horikawa Y, Oda N, Cox NJ, Li X, Orho-Melander M, Hara $\mathrm{M}$, et al. Genetic variation in the gene encoding calpain-10 is associated with type 2 diabetes mellitus. Nature genetics. 2000;26(2):163-75.

74.Hyejin Lee, Jee-Young Oh, Yeon-Ah Sung, Hyewon Chung,Hyung-Lae Kim, Gwang SubKim, Yoon Shin Cho, et al.Genome-wide association study identified newsusceptibility locifor polycystic ovary syndrome. Human Reproduction, Vol.30, No.3 pp. 723-731, 2015

75. Vink JM, Sadrzadeh S, Lambalk CB, Boomsma DI. Heritability of polycysticovary syndrome in a Dutch twinfamily study. J Clin Endocrinol Metab2006;91:2100-2104.

76.Kosova G, Urbanek M. Genetics of the polycystic ovary syndrome. Mol CellEndocrinol 2013;373:29-38.Kumar U, Sasi R, Suresh S, Patel

77.Hwang JY, Lee EJ, Jin Go M, Sung YA, Lee HJ, Heon Kwak $\mathrm{S}$, et al. Genome-wide association studyidentifies GYS2 as a novel genetic factor for polycystic ovary syndromethrough obesity-related condition. J Hum Genet 2012;57:660-664.

78.Kim JJ, Choi YM, Cho YM, Hong MA, Chae SJ, Hwang $\mathrm{KR}$,et al. Polycystic ovary syndrome is not associated withpolymorphisms of the TCF7L2, CDKAL1, HHEX, KCNJ11, FTO andSLC30A8 genes. Clin Endocrinol (Oxf) 2012;77:439-445.

79. Yun JH, Gu BH, Kang YB, Choi BC, Song S, Baek KH. Association betweenINS-VNTR polymorphism and polycystic ovary syndrome in a Koreanpopulation. Gynecol Endocrinol 2012;28:525-528.

80.Chen ZJ, Zhao H, He L, Shi Y, Qin Y, Li Z, et al. Genomewide association study identifies susceptibility loci for polycysticovary syndrome on chromosome $2 \mathrm{p} 16.3,2 \mathrm{p} 21$ and 9q33.3. Nat Genet2011;43:55-59.

81.Shi Y, Zhao H, Cao Y, Yang D, Li Z, Zhang B, et al. Genomewide association study identifies eight newrisk loci for polycysticovary syndrome. Nat Genet 2012;44:1020-1025.

82.Luque-Ramírez M, San Millán JL, Escobar-Morreale HF. Genomic variants in polycystic ovary syndrome. Clinica chimica acta. 2006;366(1):14-26

83. Valdés P, Cerda A, Barrenechea C, Kehr M, Soto C, Salazar LA. No association between common Gly972Arg variant of the insulin receptor substrate-1 and polycystic ovary syndrome in Southern Chilean women. Clinica chimica acta. 2008;390(1):63-6.

84.Azziz R, Kashar-Miller M. Family history as a risk factor for the polycystic ovary syndrome. Journal of pediatric 
endocrinology \& metabolism: JPEM. 2000;13:1303.

85.Zhang L, Guo L, Peng Y, Chen B. Expression of T-STAR gene is associatedwith regulation of telomerase activity in human colon cancer cell lineHCT-116. World J Gastroenterol 2006;12:4056-4060.

86.Gomez DE, Armando RG, Farina HG, Menna PL, Cerrudo CS, Ghiringhelli PD, Alonso DF. Telomere structure and telomerase inhealth and disease (review). Int J Oncol 2012;41:1561-1569.

87.Nordfjall K, Larefalk A, Lindgren P, Holmberg D, Roos G. Telomere lengthand heredity: indications of paternal inheritance. Proc Natl Acad Sci USA2005;102:1637416378.

88.Roger L, Jones RE, Heppel NH, Williams GT, Sampson JR, Baird DM.Extensive telomere erosion in the initiation of colorectal adenomas andits association with chromosomal instability. J Natl Cancer Inst 2013;105:1202-1211.

89.Brouilette SW, Moore JS, McMahon AD, Thompson JR, Ford I, Shepherd J,Packard CJ, Samani NJ. Telomere length, risk of coronary heart disease, and statin treatment in the West of Scotland Primary Prevention Study:a nested case-control study. Lancet 2007;369:107-114.

90.Cohen S, Janicki-Deverts D, Turner RB, Casselbrant ML, Li-Korotky HS,Epel ES, Doyle WJ. Association between telomere length andexperimentally induced upper respiratory viral infection in healthyadults. JAMA 2013;309:699-705.

91.Sahin E, Colla S, Liesa M, Moslehi J, Muller FL, Guo M, et al. Telomere dysfunction induces metabolic andmitochondrial compromise. Nature 2011;470:359-365.

92.Guo N, Parry EM, Li LS, Kembou F, Lauder N, Hussain MA, et al. Short telomeres compromise beta-cell signaling andsurvival. PLoS One 2011;6:e17858.

93.LeeHW, Blasco MA, Gottlieb GJ, Horner JW II, GreiderCW, DePinho RA.Essential role of mouse telomerase in highly proliferative organs. Nature1998;392:569-574.

94.Meredith A. Brower, Michelle R. Jones, Jerome I. Rotter, Ronald M. Krauss, Richard S. Legro, Ricardo Azziz, and Mark O. Goodarzi Further Investigation in Europeans of SusceptibilityVariants for Polycystic Ovary Syndrome Discovered inGenome-Wide Association Studies of ChineseIndividuals J Clin Endocrinol Metab, January 2015, 100(1):E182-E186.

95.Goodarzi MO, Jones MR, Li X, et al. Replication of association of DENND1A and THADA variants with polycystic ovary syndrome in European cohorts. J Med Genet. 2012;49:90-95.

96. Welt CK, Styrkarsdottir U, Ehrmann DA, et al. Variants in DENND1A are associated with polycystic ovary syndrome in women of European ancestry. JClin Endocrinol Metab. 2012;97:E1342-E1347.

97.McAllister JM, Modi B, Miller BA, et al. Overexpression of aDENND1A isoform produces a polycystic ovary syndrome thecaphenotype. Proc Natl Acad Sci USA. 2014;111:E1519E1527.

98.Wang P, Zhao H, Li T, et al. Hypomethylation of the LH/ choriogonadotropin receptor promoter region is a potential mechanism underlying susceptibility to polycystic ovary syndrome. Endocrinology.2014;155:1445-1452.

99.Urbanek M, Legro RS, Driscoll DA, Azziz R, Ehrmann DA, Norman RJ, et al. Thirty- seven candidate genes for polycystic ovary syndrome: strongest evidence for linkage is withfollistatin. Proceedings of the National Academy of Sciences. 1999;96(15):8573-8.

100.Zawadzki J, Dunaif A. Diagnostic criteria for polycystic ovary syndrome: towards a rational approach. Polycystic ovary syndrome Boston: Blackwell Scientific. 1992;377.

101.Azziz R, Woods KS, Reyna R, Key TJ, Knochenhauer ES,
Yildiz BO. The prevalence and features of the polycystic ovary syndrome in an unselected population. Journal of Clinical Endocrinology \& Metabolism. 2004;89(6):2745-9.

102.Govind A, Obhrai M, Clayton R. Polycystic ovaries are inherited as an autosomal dominant trait: analysis of 29 polycystic ovary syndrome and 10 control families

103. Gonzalez A, Abril E, Roca A, Aragón MJ, Figueroa MJ, Velarde P, et al. CAPN10 alleles are associated with polycystic ovary syndrome. Journal of Clinical Endocrinology \& Metabolism. 2002;87(8):3971-6

104. Dr Dariush Farhud, Noushin Niknat, Dr. Mahmood Mahmoodi, Attitude of a group of doctors, nurses and midwives in Tehran on the principles of ethics in medical genetics, Iranian Journal of Health, Vol. 28, No. 1-4,1378.

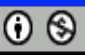

This work is licensed under a Creative Commons AttributionNon Commercial 4.0 International License. 